\title{
Protecting Peroxidase Activity of Multilayer Enzyme-Polyion Films Using
}

\section{Outer Catalase Layers}

\author{
Haiyun Lu, ${ }^{\mathrm{a}}$ James F. Rusling, ${ }^{\mathrm{b}, \mathrm{c}}$ Naifei $\mathrm{Hu}^{* \mathrm{a}}$
}

${ }^{a}$ Department of Chemistry, Beijing Normal University, Beijing 100875, P. R. China

${ }^{\mathrm{b}}$ Department of Chemistry, University of Connecticut, U-60, Storrs, CT 06269-3060, USA

${ }^{\mathrm{c}}$ Department of Pharmacology, University of Connecticut Health Center, Farmington, CT 06032, USA

*Corresponding author. Tel.: +86 105880 5498; fax: +86 105880 2075. E-mail address: hunaifei@bnu.edu.cn (N. Hu).
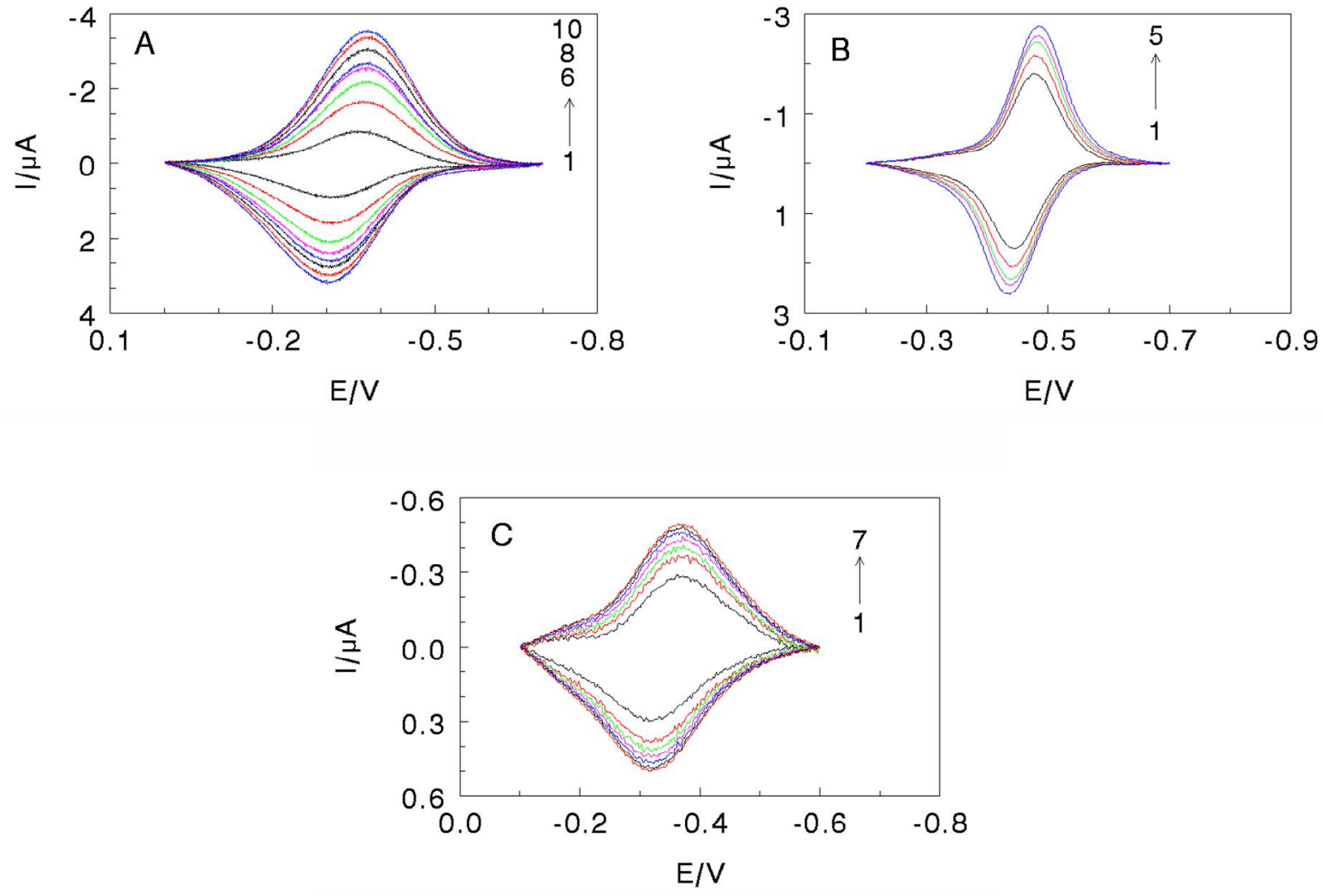
Figure S1. Background-subtracted $\mathrm{CVs}$ at $0.2 \mathrm{~V} \mathrm{~s}^{-1}$ in $\mathrm{pH} 7.0$ buffers for (A) $\{\mathrm{Mb} / \mathrm{HA}\}_{\mathrm{n}},(\mathrm{B})$ $\{\text { catalase } / \mathrm{HA}\}_{\mathrm{n}}$, and $(\mathrm{C})\{\mathrm{HRP} / \mathrm{HA}\}_{\mathrm{n}}$ films assembled on PG/chitosan/HA electrodes.

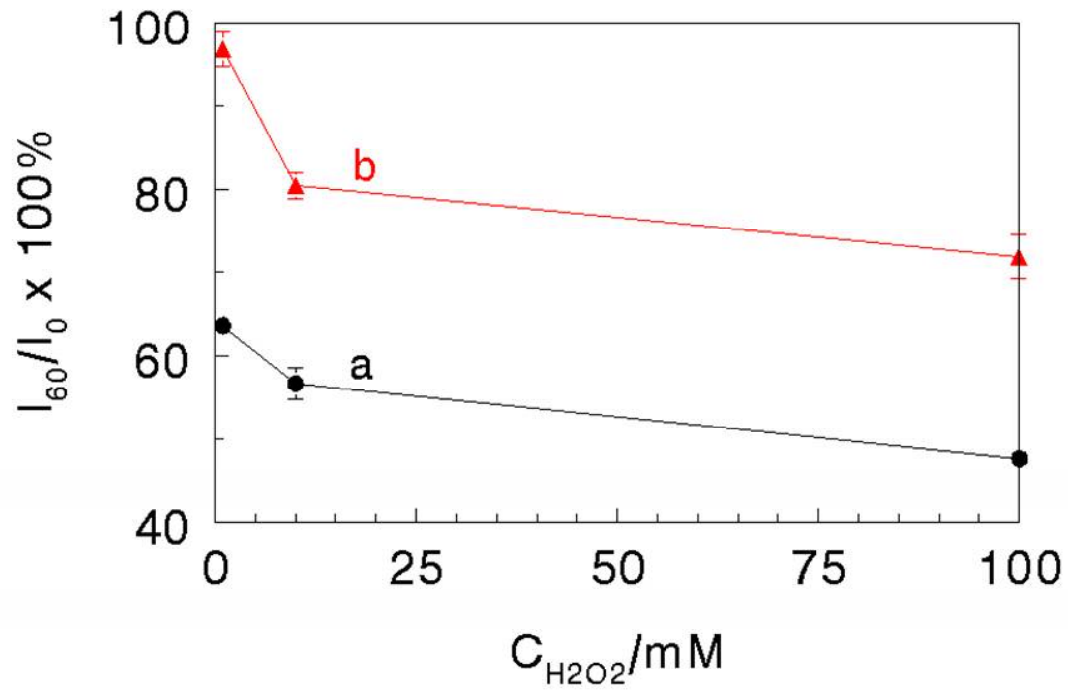

Figure S2. Influence of $\mathrm{H}_{2} \mathrm{O}_{2}$ concentration $\left(\mathrm{C}_{\mathrm{H} 2 \mathrm{O} 2}\right)$ in incubation solutions on $\mathrm{CV}$ reduction peak current ratio $\left(\mathrm{I}_{60} / \mathrm{I}_{0}\right)$ for (a) $\{\mathrm{Mb} / \mathrm{HA}\}_{10}$ and (b) $\{\mathrm{Mb} / \mathrm{HA}\}_{10} /\{\text { catalase } / \mathrm{HA}\}_{4} /$ catalase films. CVs were performed at $0.2 \mathrm{~V} \mathrm{~s}^{-1}$ in $\mathrm{pH} 7.0$ buffers after the incubation.

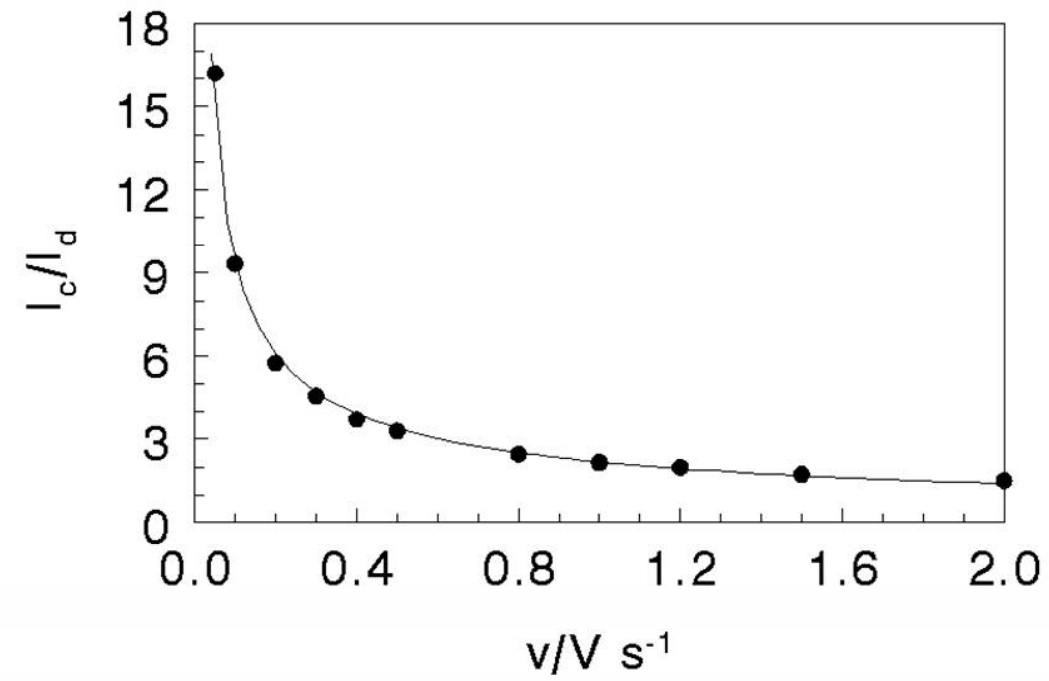


Figure S3. Influence of scan rate on catalytic efficiency, $\mathrm{I}_{\mathrm{c}} / \mathrm{I}_{\mathrm{d}}$, for $\{\mathrm{Mb} / \mathrm{HA}\}_{25}$ films in $\mathrm{pH} 7.0$ buffers, where $I_{d}$ and $I_{c}$ are the $C V$ reduction peak current in the absence and presence of $0.1 \mathrm{mM} \mathrm{H}_{2} \mathrm{O}_{2}$, respectively.

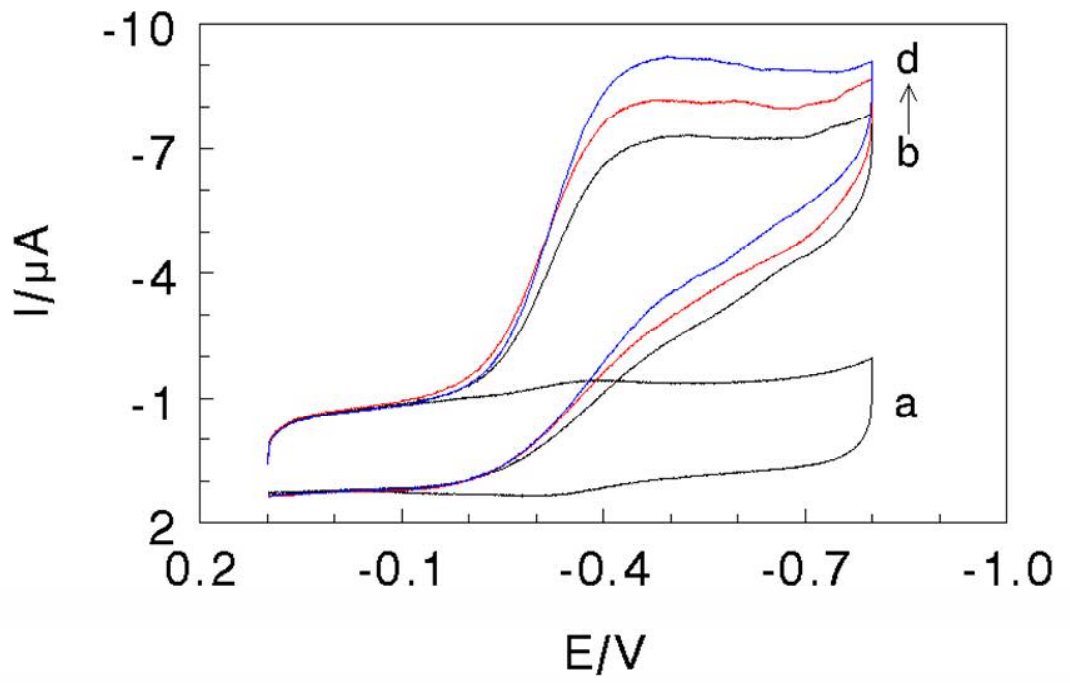

Figure S4. CVs at $0.2 \mathrm{~V} \mathrm{~s}^{-1}$ in $\mathrm{pH} 7.0$ buffers for (a) $\{\mathrm{HRP} / \mathrm{HA}\}_{25}$ films in the absence of $\mathrm{H}_{2} \mathrm{O}_{2}$, (b) $\{\mathrm{HRP} / \mathrm{HA}\}_{25}, \quad$ (c) $\{\mathrm{HRP} / \mathrm{HA}\}_{25} /$ catalase, and (d) $\{\mathrm{HRP} / \mathrm{HA}\}_{25} /$ catalase/HA/catalase films in the presence of $0.1 \mathrm{mM} \mathrm{H}_{2} \mathrm{O}_{2}$.

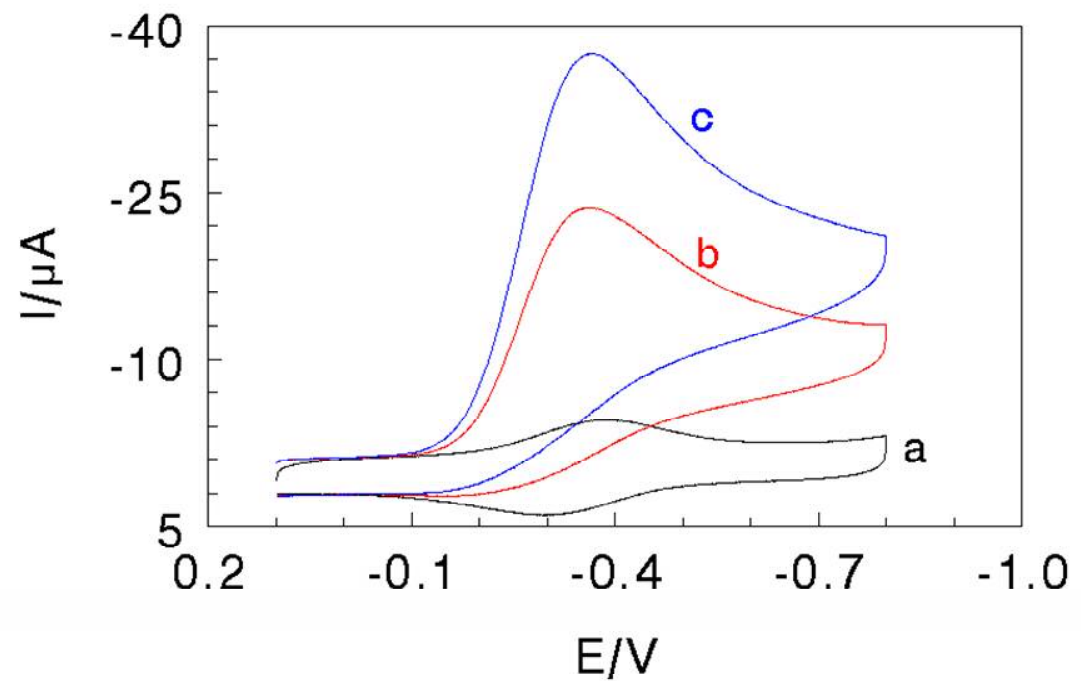


Figure S5. CVs at $0.2 \mathrm{~V} \mathrm{~s}^{-1}$ in $10 \mathrm{~mL}$ of $\mathrm{pH} 7.0$ buffers for (a) $\{\mathrm{Mb} / \mathrm{HA}\}_{25}$ films, (b) $\{\mathrm{Mb} / \mathrm{HA}\}_{25}$ films after $20 \mathrm{~mL}$ of air was injected, (c) $\{\mathrm{Mb} / \mathrm{HA}\}_{25}$ films after $40 \mathrm{~mL}$ of air was injected.
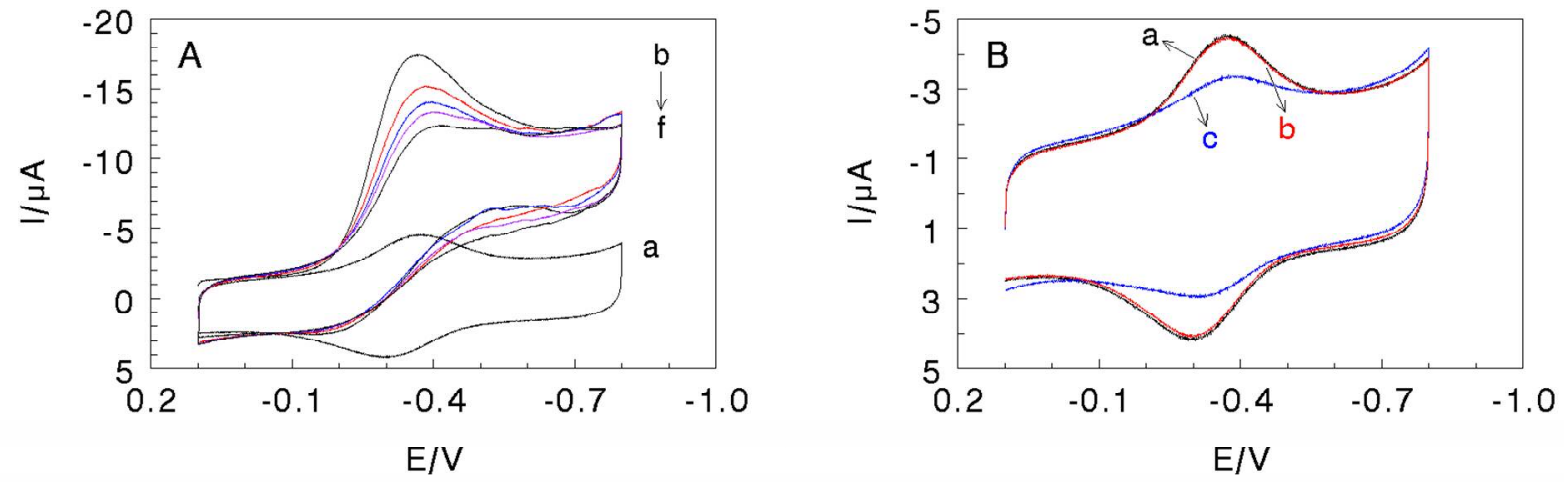

Figure S6. (A) CVs at $0.2 \mathrm{~V} \mathrm{~s}^{-1}$ in $\mathrm{pH} 7.0$ buffers for $\{\mathrm{Mb} / \mathrm{HA}\}_{10}$ films (a) in the absence of $\mathrm{H}_{2} \mathrm{O}_{2}$; and in the presence of $0.1 \mathrm{mM} \mathrm{H}_{2} \mathrm{O}_{2}$ of the (b) 1st, (c) 5th, (d) 10th, (e) 15th, and (f) 20th cycle of continuous CV scans. (B) CVs at $0.2 \mathrm{~V} \mathrm{~s}^{-1}$ in $\mathrm{pH} 7.0$ buffers for $\{\mathrm{Mb} / \mathrm{HA}\}_{10}$ films (a) before incubation, (b) after being incubated in $0.1 \mathrm{mM} \mathrm{H}_{2} \mathrm{O}_{2}$ solutions for $3 \mathrm{~min}$, and (c) after 20 cycles of continuous $\mathrm{CV}$ scans in $0.1 \mathrm{mM} \mathrm{H}_{2} \mathrm{O}_{2}$. 